\title{
Letter
}

\section{Cardiac arrest following a glucose $30 \%$ bolus: what happened?}

Philippe Goutorbe ${ }^{1}$, Nadia Kenane ${ }^{1}$, Julien Bordes ${ }^{1}$, Christophe Jego ${ }^{2}$, Ambroise Montcriol ${ }^{1}$ and Eric Meaudre ${ }^{1}$

${ }^{1}$ HIA Ste Anne Daru, Bd Ste Anne, 83000 Toulon, France

${ }^{2} \mathrm{HIA}$ Ste Anne Cardiology, Bd Ste Anne, 83000 Toulon, France

Corresponding author: Philippe Goutorbe, philippe.goutorbe@neuf.fr

Published: 16 January 2008

This article is online at http://ccforum.com/content/12/1/401

(c) 2008 BioMed Central Ltd

A 74-year-old man was admitted with postoperative peritonitis. On day 45, a double-lumen central venous catheter was positioned in the patient's right subclavian vein. The distal lumen was used only for parenteral nutrition $(2,000 \mathrm{ml} /$ day Kabiven ${ }^{\circledR}$ 1600; Fresenius Kabi Brezin, France). Glucose 5\% $(250 \mathrm{ml})$ with $6 \mathrm{~g}$ potassium was infused, over 24 hours, via the proximal lumen. Hypokalemia was noted $\left(\mathrm{K}^{+}, 3.0 \mathrm{mEq} / \mathrm{l}\right)$. An additional infusion of potassium was initiated (34 $\mathrm{mEq}$ in $10 \mathrm{ml}$, at $17 \mathrm{mEq} /$ hour) via the proximal lumen.

One hour later hypoglycemia was detected, and $20 \mathrm{ml}$ of $30 \%$ glucose was given intravenously. At the end of the injection, ventricular fibrillation developed. Cardiopulmonary resuscitation successfully restored adequate circulation within 12 minutes. Blood analysis performed using an $A B L$ 700 (Radiometer, Copenhagen, Denmark) 1 minute after
Critical Care 2008, 12:401 (doi:10.1186/cc6216)

beginning cardiac resuscitation showed serum potassium of $5.1 \mathrm{mmol} / \mathrm{l}$, ionised calcium of $1.1 \mathrm{mmol} / \mathrm{l}$, and serum sodium of $140 \mathrm{mmol} / \mathrm{l}$. The empty ampoule was checked, and had contained the correct solution. The cardiac rhythm had been normal before the glucose bolus was given, but sinus arrest with junctional or idioventricular escape rhythm developed at the end of bolus administration, immediately followed by ventricular fibrillation (Figure 1). The patient was discharged 2 weeks later without any sequelae.

Electrocardiographic changes are not usually seen until serum potassium exceeds $6.0-6.5 \mathrm{mmol} / \mathrm{l}$. Disappearance of the $P$ wave is usually seen when serum potassium exceeds $8 \mathrm{mmol} / \mathrm{l}[1]$. We were surprised, however, to find changes in the absence of any increase in serum potassium. There was neither hyponatremia nor hypocalcemia, both of which

\section{Figure 1}
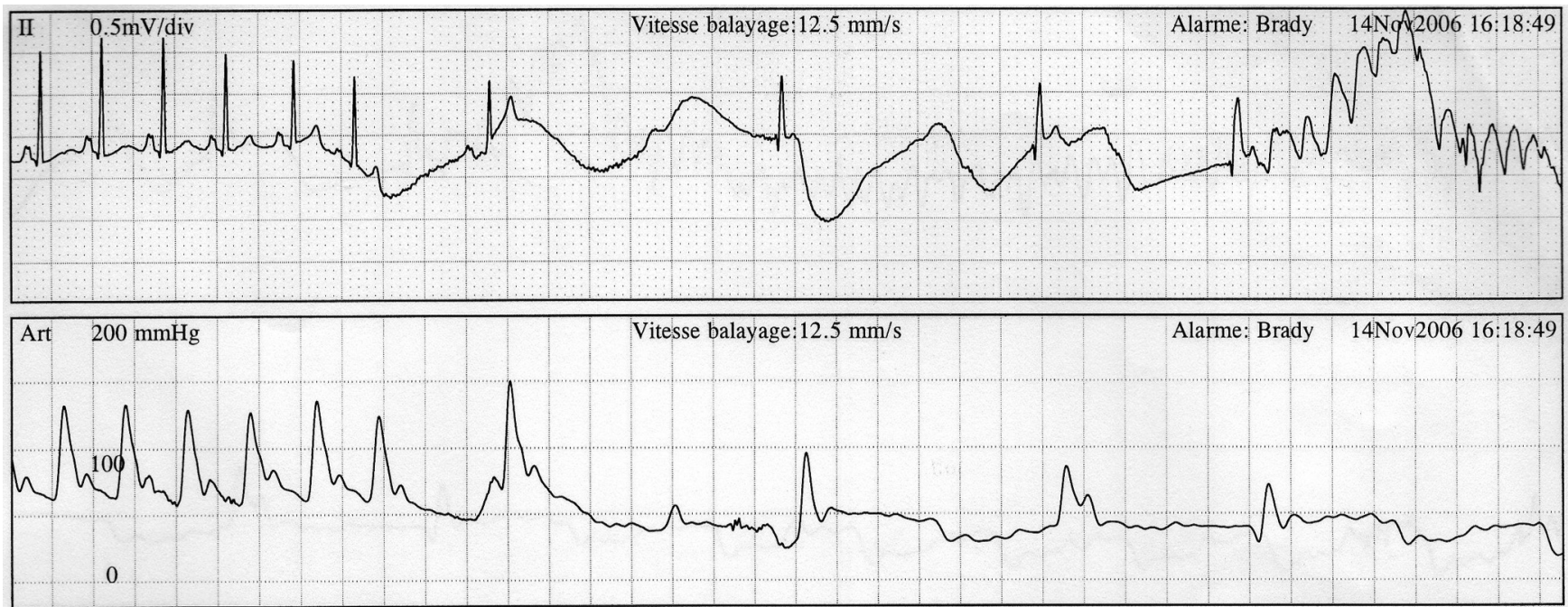

Traces of the monitoring storage during glucose injection. The upper trace is an electrocardiogram showing sinus arrest, idioventricular or junctional escape rhythm immediately followed by ventricular fibrillation. The lower trace is the blood pressure. 
increase sensitivity to hyperkalemia [2,3]. Even if serum potassium was normal, we think it possible there could have been local hyperkalemia, which led to sinus arrest and then to ventricular fibrillation. The mechanism of this hyperkalemia, we postulate, is that the high potassium concentration $(1,074 \mathrm{mmol} / \mathrm{l})$ in the deadspace of the tubing was flushed by the glucose, corresponding to a $11 \mathrm{mEq}$ intravenous bolus of $\mathrm{K}^{+}$.

The present case highlights a dangerous aspect of using concentrated solutions for $\mathrm{K}^{+}$therapy. Although an infusion rate of $17 \mathrm{mEq} /$ hour is usually considered safe, in the particular situation here, with a central venous catheter in an intrathoracic position, flushing the catheter created a bolus injection. Theoretically, such a poorly mixed bolus can cause dangerous concentrations in the coronary arteries. When using potassium supplements, catheters with minimum deadspace are preferable, and bolus injections should be avoided.

\section{Competing interests}

The authors declare that they have no competing interests.

\section{References}

1. Bonvini RF, Hendiri T, Anwar A: Sinus arrest and moderate hyperkalemia. Ann Cardiol Angeiol (Paris) 2006, 55:161-163.

2. Mehta NJ, Chhabra VK, Khan IA: Sinus arrest or sinoventricular conduction in mild hyperkalemia. J Emerg Med 2001, 20:163164.

3. Johnston $\mathrm{HL}$, Murphy R: Agreement between an arterial blood gas analyser and a venous blood analyser in the measurement of potassium in patients in cardiac arrest. Emerg Med J 2005, 22:269-271. 